\title{
Monitor and Study Horizontal and Verticals Changes at Land Surface in Wen Chuan Area from 1974 to 2010 Using Remote Sensing and GIS Technology
}

\section{Mohamed Mhmod ${ }^{1 *}$, Liu Cai ${ }^{2}$ and Meng Zhuoguo ${ }^{3}$}

${ }^{1}$ Jilin University, College, Geo Exploration Science and Technology, China

2Jilin University Geo Exploration and Technology College, China

${ }^{3}$ JilinUniversity College of Geo Exploration Science and Technology, Remote Sensing, China

\begin{abstract}
Wenchuan area has been one of the seismically active regions. The occurrences of earthquakes are largely controlled by active faults. The results showed that in Wenchuan area, movements of plate tectonic were not in the same direction in recent 40 years and when there was a change in the direction of plate tectonics there was an earthquake in Sichuan, or on Tibet plate, but most of the earthquakes were in the region between plate Sichuan and Tibet plate. The idea is to compare between images from the same satellite for same area in different years by using remote sensing and GIS technology. The result will become better if there are images of the same area every year.

The satellite images were used from 1974-1976 land sat-1,2, 1989-1996 land sat-4,1999-2005 land sat -7, Google earth images 2005-2008 after and before the earthquake Wenchuan 2008, Geomorphic features are extracted from the Shuttle Radar Topography Mission (SRTM) DEM data 2002 and 2010, SRTM DEM and Land sat data were used to extract the geo morphometric Features and structures. The relationship between the topography and tectonics is assessed to understand the evolution mode.
\end{abstract}

Keywords: Horizontal and verticals changes; Wen Chuan; Remote sensing; GIS

\section{Introduction}

In recent years, remote sensing and geographic information systems and other technology rapid development and wide application of Land has become an effective means of status and temporal evolution of the process, providing a dynamic information environment is difficult to obtain conventional methods to solve complex spatial problems for the conduct of regional dynamic monitoring provides favorable conditions.

\section{General information about study area}

Wenchuan Sichuan is located in the northwest edge of Sichuan Basin, at Aba Tibetan and Qiang Autonomous Prefecture, and one of the four counties inhabited by the Qiang Chinese Autonomous Prefecture On May 12, 2008, earthquake struck Wenchuan 7.9 MW eastern edge of the Tibetan plateau, destroyed cities along the northwest margin of the Sichuan Basin, caused more than 80,000 dead and 380,000 wounded (Figure 1).

\section{Tectonic and geology setting of Wenchuan}

The active tectonic map of the study area and around it, shows the different kind of the fault, where there are reveres, strike-slip ruptures (Figure 2). Sequence was imbricate and emplaced eastward over the lower structural sequence in Late Triassic to Middle Jurassic time. Transitional units between the two structural sequences are generally not found. Thrust sheets over ride the older fore deep deposits, and thrust contacts are sealed in places by Middle Jurassic strata, constraining the end of thrusting to the pre-Middle Jurassic. The fore deep deposits continue into the Late Cretaceous, but large postMiddle Jurassic, pre-Oligocene structures have not been identified. The Mesozoic thrust complex and its underlying autochthon were refolded

\section{Brief about Work Methods}

Determine the study area with four coordinates and download satellite images then used software (ENVI) to cut the images so that they cover the study area. Also cut Digital elevations images (DEM) so that they cover the study area because definitely there is no image can just cover this chosen study area. That's why it needs to cut or collect more than one image to cover this area. Due to the poor data for the same satellite during a period of 40 years. Therefore has been studied - specific years that the necessary data are available and make comparisons between them.

As well as the benefit from the program Google Earth free as the software provided with aerial photographs and satellite images with geographical coordinates of and the advantage in the use of landmarks apparent on all pictures between the years 2005-2010 as points of GPS (Flow Chart 1).

\section{Study Materials and Data Methodology and Results}

Remote sensing is used as a tool to extract information about the land surface structure, composition or subsurface, but is often combined with other data sources providing complementary measurements. Multispectral data can provide information on lithology or rock composition based on spectral reflectance. Radar provides an expression of surface topography and roughness, and thus is extremely valuable,

*Corresponding author: Mohamed Mhmod, PhD student at Jilin University, College, Geo exploration Science and Technology, China, Tel: +8615526896918: E-mail: baveciwan-23@hotmail.com

Received April 24, 2015; Accepted June 24, 2015; Published July 01, 2015

Citation: Mhmod M, Cai L, Zhuoguo M (2015) Monitor and Study Horizontal and Verticals Changes at Land Surface in Wen Chuan Area from 1974 to 2010 Using Remote Sensing and GIS Technology. J Remote Sensing \& GIS 4: 146. doi:10.4172/2469-4134.1000146

Copyright: $\odot 2015$ Mhmod M, et al. This is an open-access article distributed under the terms of the Creative Commons Attribution License, which permits unrestricted use, distribution, and reproduction in any medium, provided the original author and source are credited. 


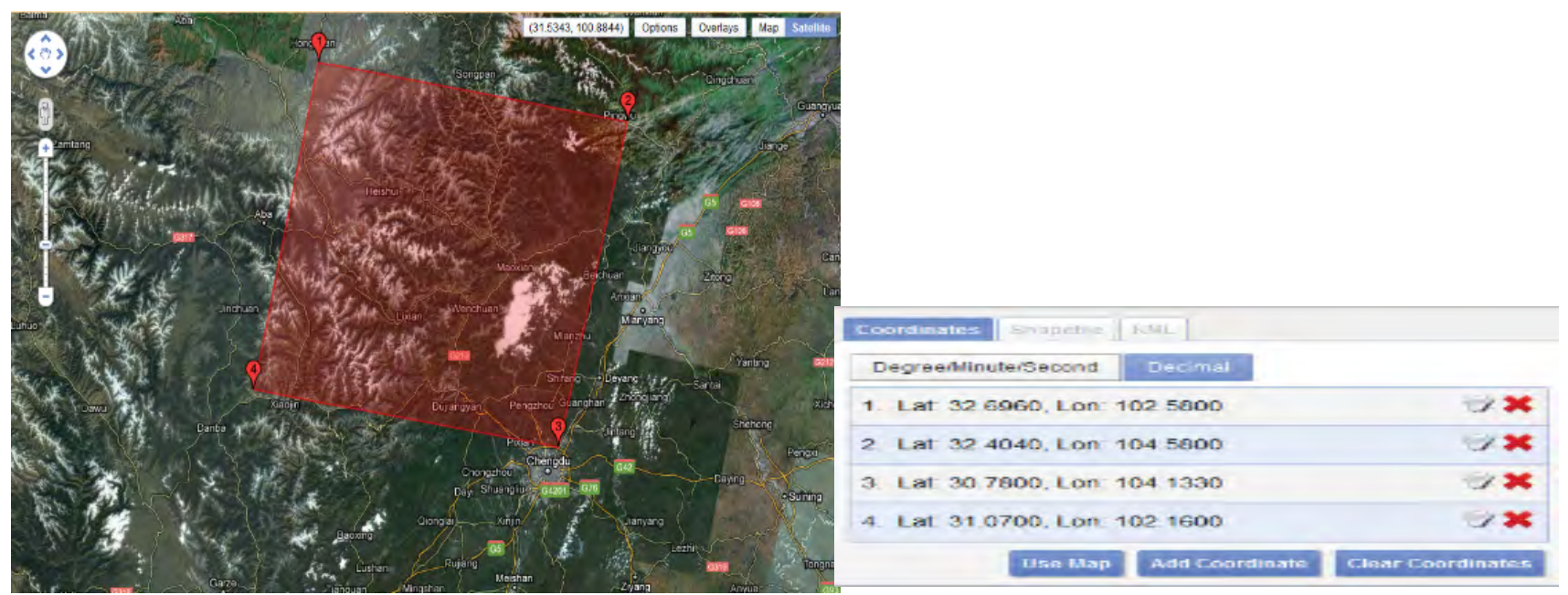

Figure 1: Study area map with four coordinated.

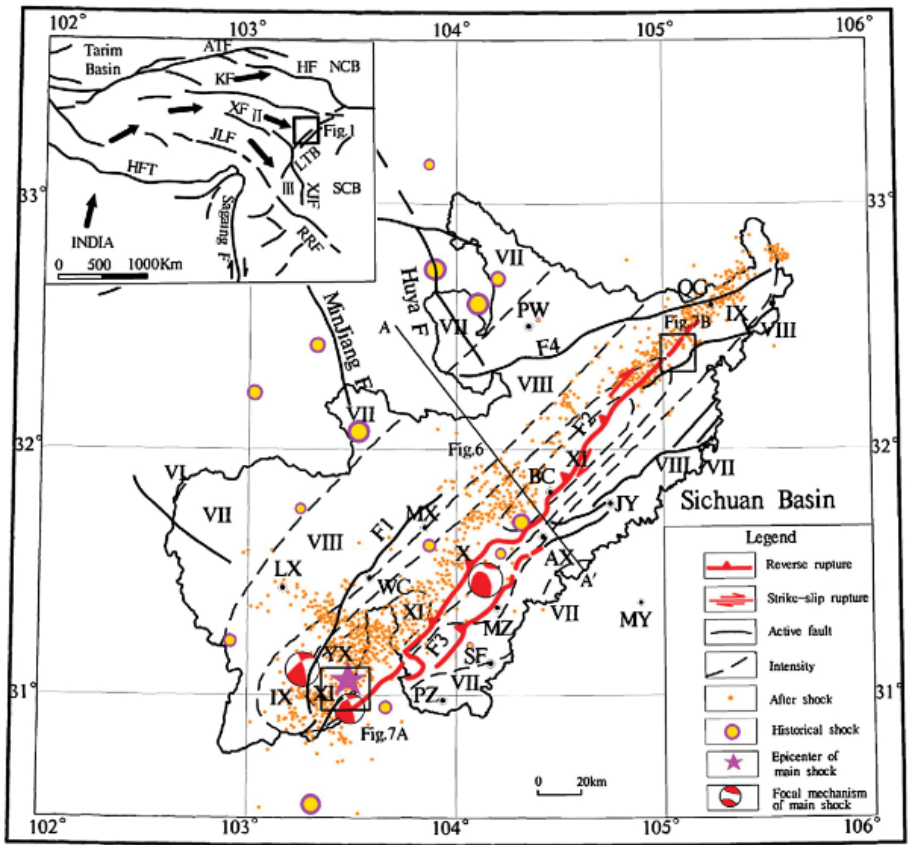

Figure 2:Active tectonic map of the study area and the surface rupture zones induced by the earthquake (Revised after Xu et al.).

especially when integrated with another data source to provide detailed relief. Remote sensing is not limited to direct geology applications - it is also used to support logistics, such as route planning for access into a mining area, reclamation monitoring, and generating base maps upon which geological data can be referenced or superimposed Geological applications of remote sensing include the following: surficial deposit/ bedrock mapping - lithological mapping, structural mapping - sand and gravel (aggregate) exploration/exploitation, mineral exploration hydrocarbon exploration, environmental geology geobotany, baseline infrastructure - sedimentation mapping and monitoring

Event mapping and monitoring - geo-hazard mapping - planetary mapping
Geological application of remote sensing includes the following:

\section{Data methodology and results}

I. Processing stage::-geometric correction: Geometric correction: conversion of data to ground coordinates by removal of distortions from sensor geometry, enable mapping relative to data layers enable and comparison.The used images (land sat $2,4,7$ ) were provide with coordinated of four corner of the images which used for geometric correction $[1,2]$.

\section{II. special processing}

A. A image transformation, Image filtering, Final processing:

B. Image enhancement: in order to aid visual interpretation, visual 


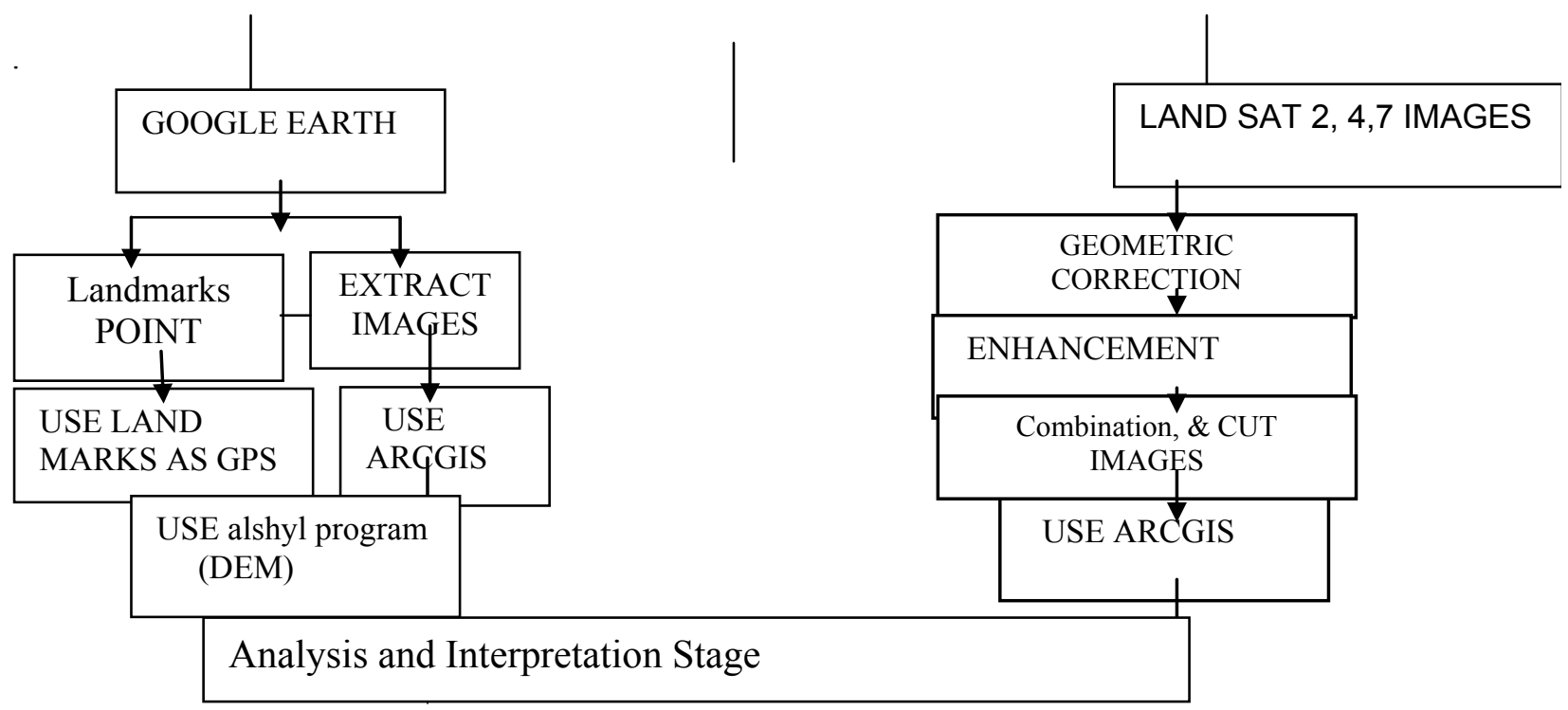

Flow Chart 1: The way of the work.

appearance of the objects in the image can be improved by image enhancement techniques such as grey level stretching to improve the contrast and spatial filtering for enhancing the edges (Figure 3).

Identify faults on satellite images Horizontal changes: Tectonic movements are divided into vertical (radial) and horizontal (tangential) movements. This distinction is of fundamental importance, although it is somewhat arbitrary because the movements are interrelated and change into one another. Tectonic movements with a predominant vertical or horizontal component. Predominant vertical movements cause the uplifting and subsidence of the earth's surface, including the formation of mountain structures. Such movements are the basic cause of the accumulation of thick sedimentary layers in the oceans and seas and, in part, on land. Horizontal movements are evidenced most strikingly in the formation of faults along which individual crustal blocks are displaced by hundreds or even thousands of kilometers relative to other blocks and in the over thrusting of crustal blocks for hundreds of kilometers. It has been argued that horizontal movements are also reflected in the formation of ocean basins thousands of kilometers wide through the moving apart of blocks of continental crust. Movements of the crust and the entire lithosphere are three-dimensional. Depending on the geodynamic stress state, some regions are dominated by vertical movements and others, by horizontal movements. The vertical component is best reflected in the topographies of the crustal base and of the Earth's surface in organic regions. This component can readily be studied by geological, geodetic, and other methods. Horizontal movements manifest themselves less evidently, particularly in flat areas, where the vertical component is small, and it is very difficult to identify them by traditional methods. In this respect, GPS measurements open new possibilities for such investigations. The method and way of work for horizontal changes were through drawing the network of rivers and faults on a set satellite images taken from the same satellite on the same region during different years and then display the faults, network of rivers plotted [3].Then comparison and monitoring the changes Images were used

- Land sat - 2, 1 from 1974-1976 (Figure 4)

- Land sat 4-5 from 1989-1996 (Figure 5)

- Land sat 7 from 1999-2005 (Figure 6)

Horizontal changes refer to the movements on $(\mathrm{X}, \mathrm{Y})$ direction.

Horizontal movements using Google earth points (2005-2008): Here we will take a group of parameters (house, school, etc ....) and clear that appear on all images as a point of GPS and that of others is possible that there will be a change in its position due to human activity (Figure 7).

For example: Select one corner of a school, write its coordinates, then select the same corner on another photo during a different time period and determine the coordinates. After that convert geographic coordinates (photos in Google has been taken with geographic coordinates) to the coordinates (X., Y) then compared between new coordinates the old coordinates.

Choose some clear points (these points cover most of the study area) before and after earth quake in Wenchuan (12 may 2008) [1] then compare between the coordinated of same point before and after earth quack (on 2 different images for same point's (Figures 8-11).

\section{Results and Conclusion}

The method and way of work for horizontal changes were through drawing the network of rivers and faults on a setsatellite imagestaken from the same satellite on the same region during different years and then display the faults, network of rivers plotted .Then comparison and monitoring the changes (Figures 12-16).

\section{Conclusion}

- From result in Wenchuan, movements of plate were not in the 


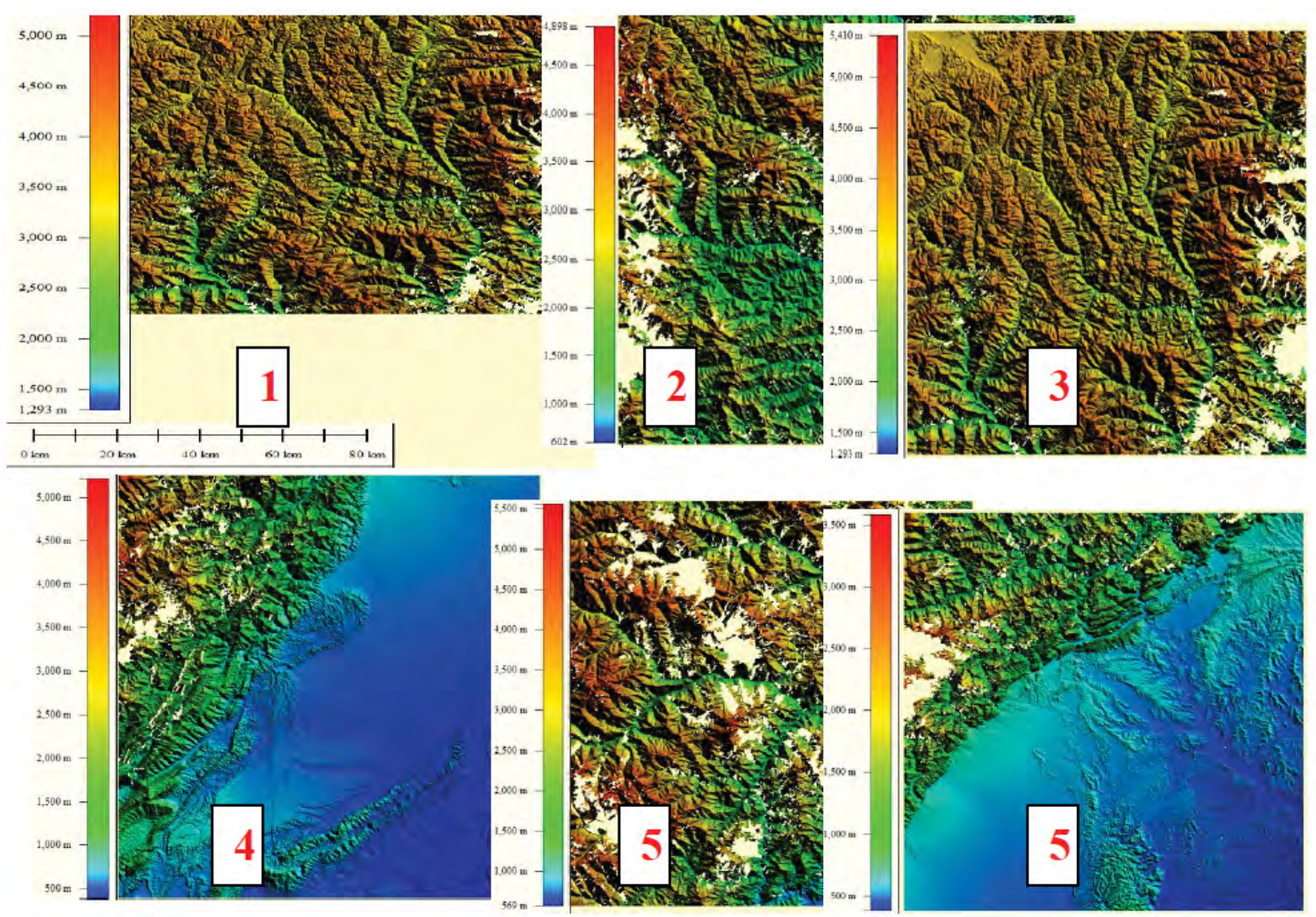

Figure 3: Use global mapper to collect all DEM images in one image: here collect image from SRTM 2002 to cover study area.
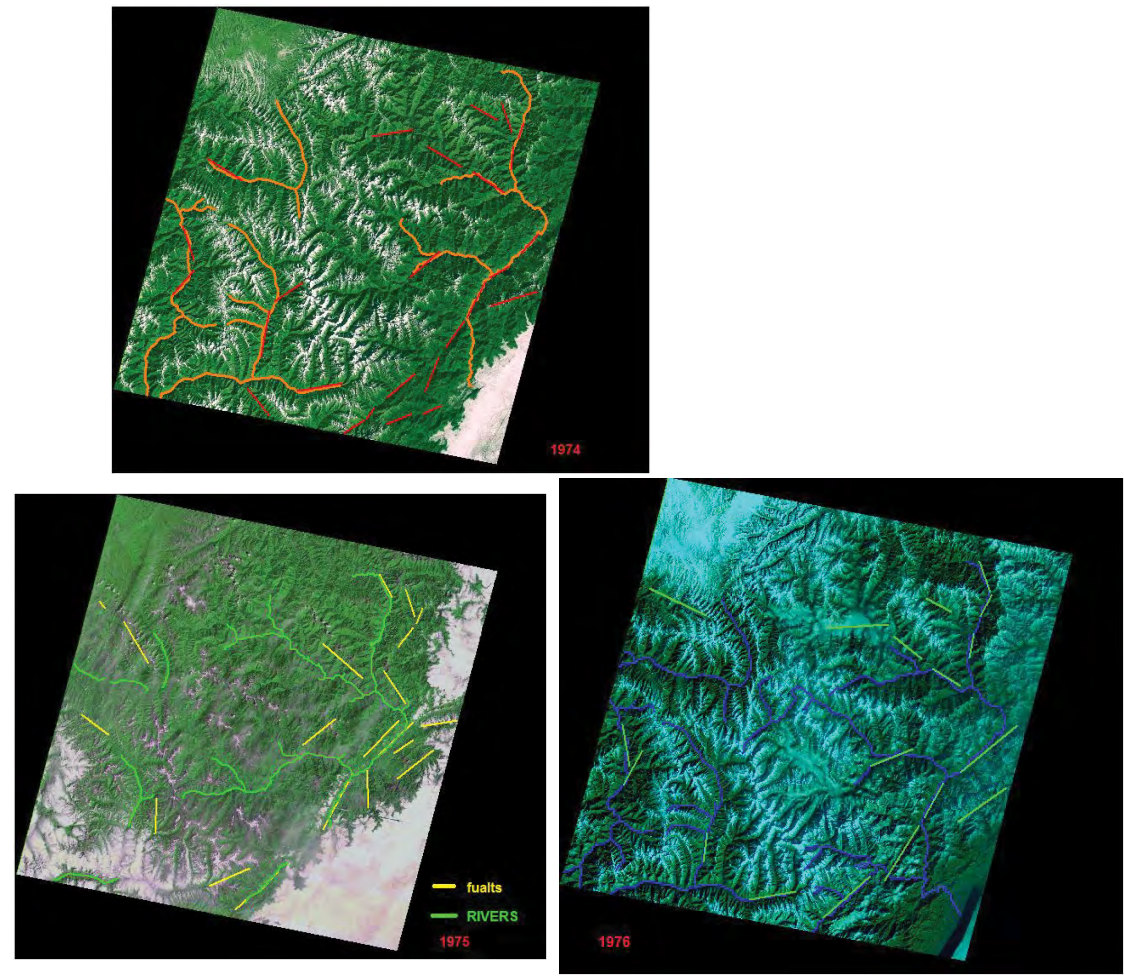

Figure 4: LAND SAT-2 1974-1976 images: Using WD World Geodetic Syst1972. 

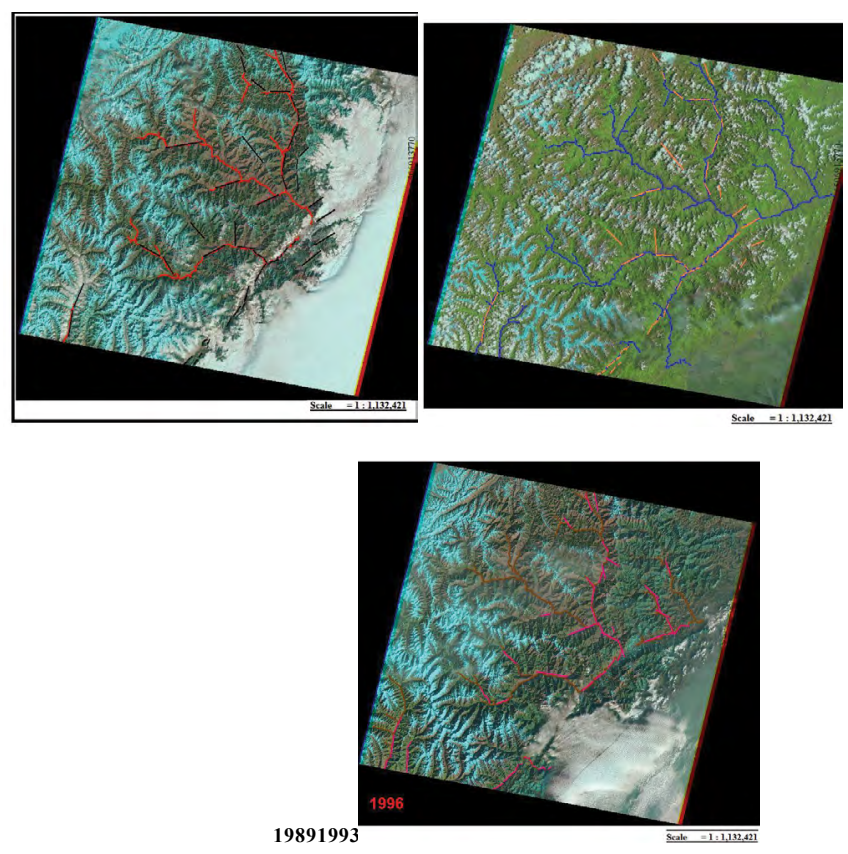

Figure 5: Images 14 -5TM 1989-1996.

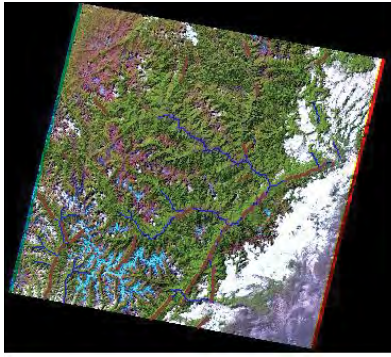

1999

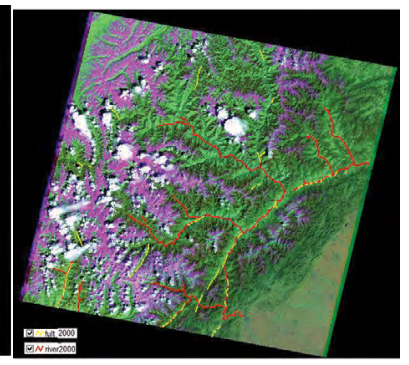

2000

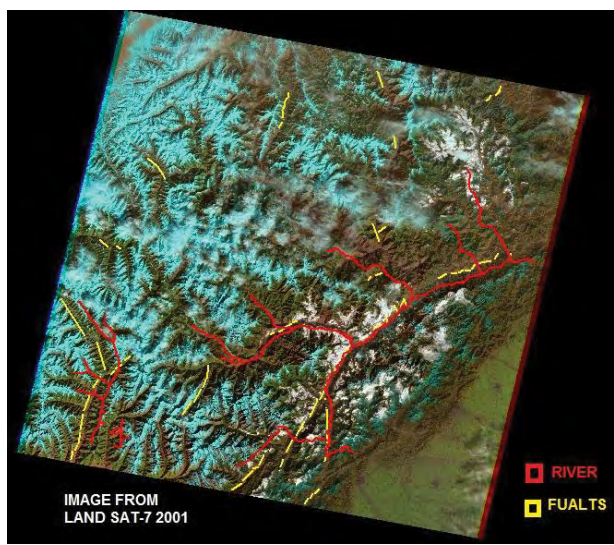

Figure 6: LAND SAT-7 images 1999-2001. 


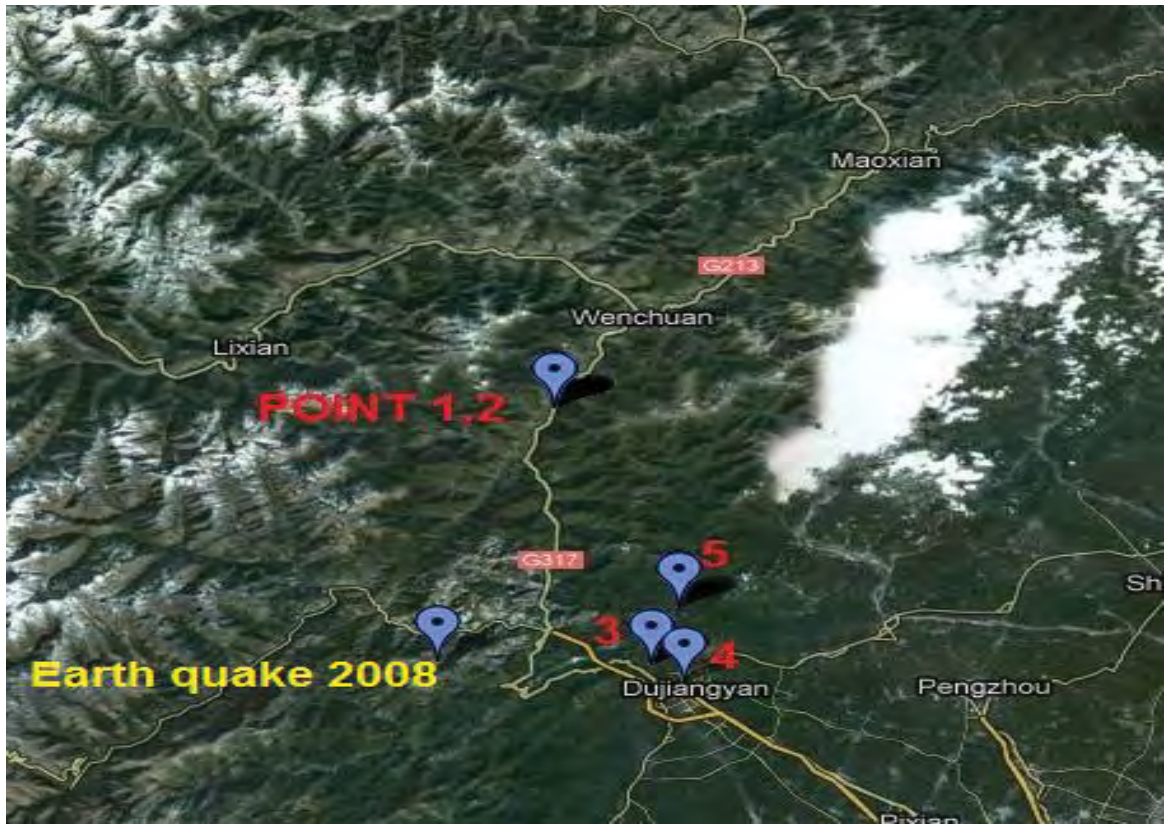

Figure 7: Image shows the point took as GPS landmarks.

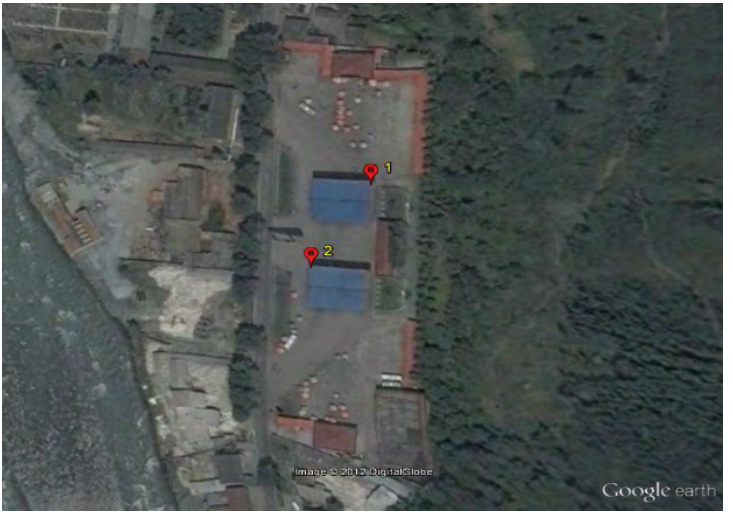

Points (B1, B2) taken in 8/9/2005

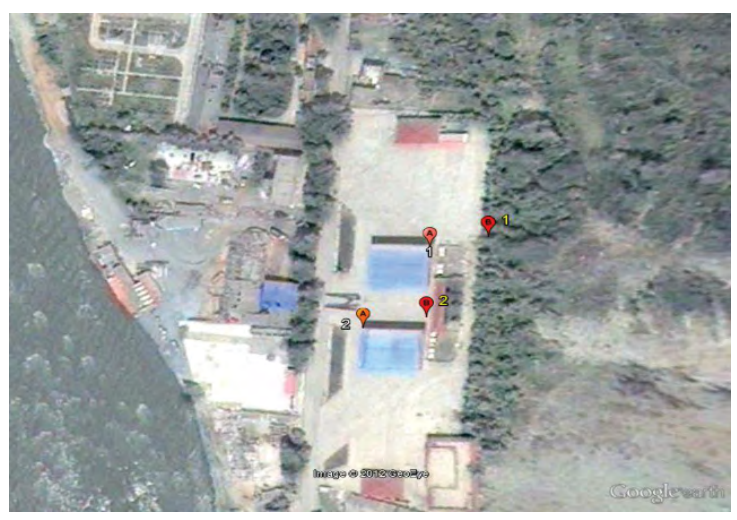

shows (A1, A2) they are the same points (B1, B2-8/9/2005) but on image 5/22/2008.

\begin{tabular}{|c|c|c|c|c|c|}
\hline \multicolumn{2}{|c|}{ 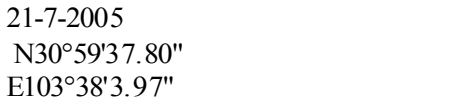 } & \multicolumn{2}{|l|}{$\begin{array}{l}30-3-2006 \\
\mathrm{~N} 30^{\circ} 59^{\prime} 37.41^{\prime \prime N} \\
\mathrm{E} 103^{\circ} 38^{\prime} 4.50^{\prime \prime} \mathrm{E}\end{array}$} & \multicolumn{2}{|l|}{$\begin{array}{l}27-6-2008 \\
30^{\circ} 59^{\prime} 37.16^{\prime \prime} \mathrm{N} \\
103^{\circ} 38^{\prime} 4.09^{\prime \prime} \mathrm{E}\end{array}$} \\
\hline & $103^{\circ} 29^{\prime} 42.76^{\prime \prime}$ & $\begin{array}{r}\text { rthing: } \\
3470166.7 \\
\end{array}$ & & $\begin{array}{l}\text { Northing: } \\
3470160 \text {. }\end{array}$ & N 5.8 \\
\hline 2 & $\begin{array}{l}\mathrm{N} 31^{\circ} 21^{\prime} 24.41^{\prime \prime} \\
\mathrm{E} 103^{\circ} 29^{\prime} 41.73 " \mathrm{E}\end{array}$ & $\begin{array}{l}\text { E356846.5 } \\
\quad \text { N3470121. } \\
8\end{array}$ & $\begin{array}{l}\mathrm{N} 31^{\circ} 21^{\prime} 24.18^{\prime \prime N} \\
\mathrm{E} 103^{\circ} 29^{\prime} 40.62^{\prime \prime}\end{array}$ & $\begin{array}{c}\text { E } 356817.1 \mathrm{~N} \\
3470115.1\end{array}$ & $\begin{array}{l}\text { E } 29.4 \\
\text { N } 6.4\end{array}$ \\
\hline
\end{tabular}

Figure 8: compeer tow images, before and after earth 5/12/2008. 


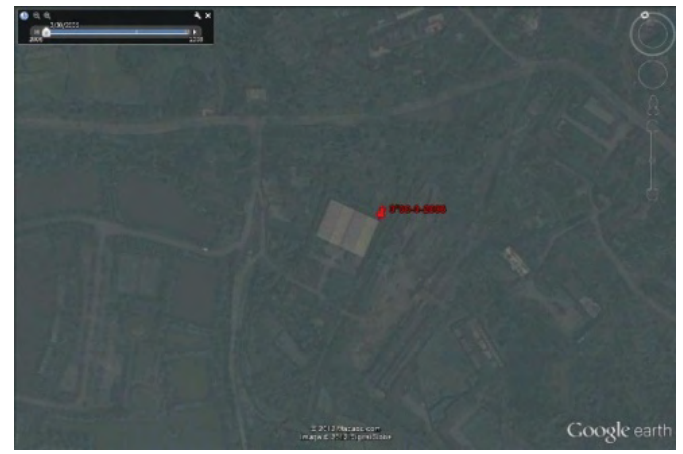

30-3-2006
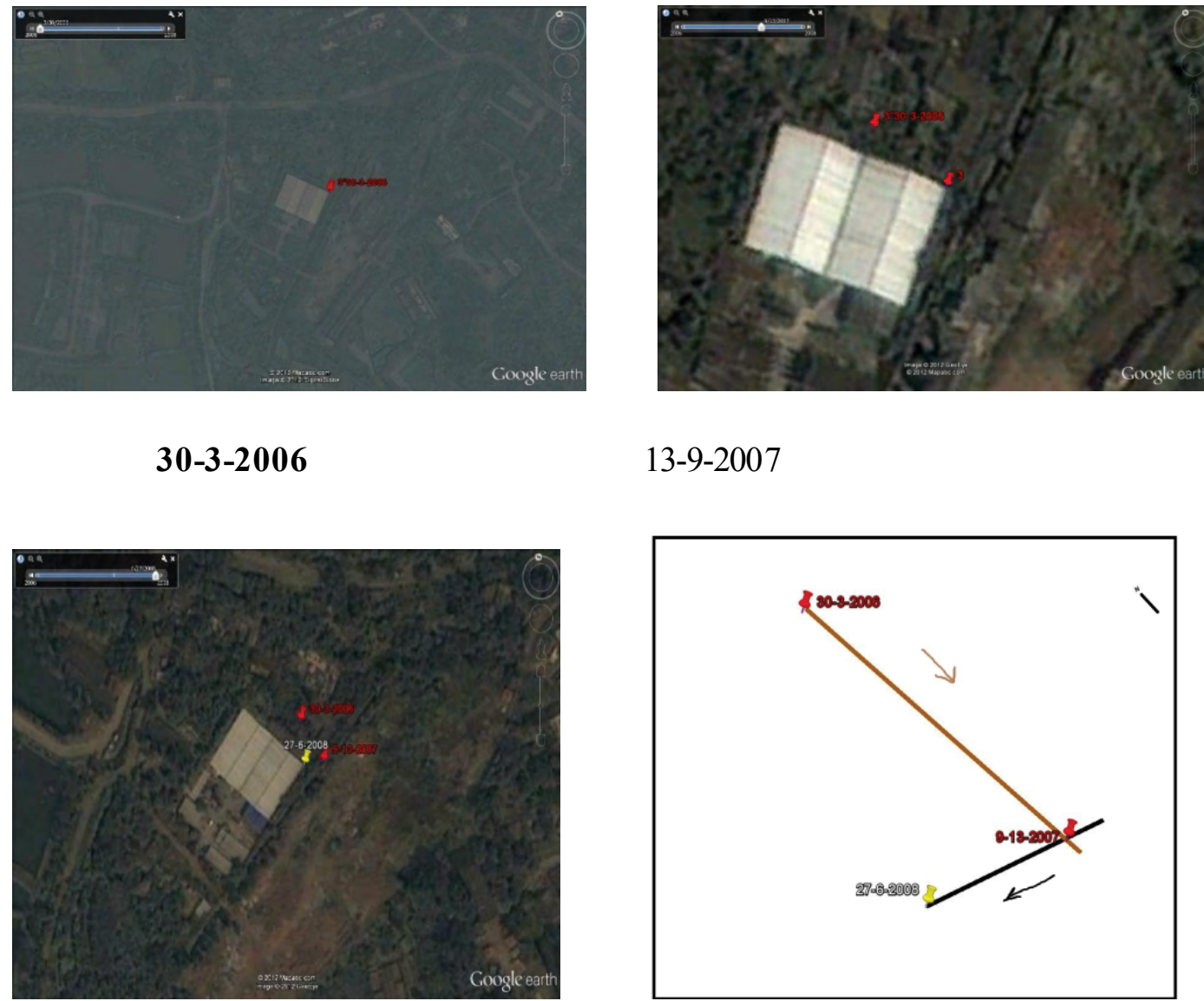

$13-9-2007$

\section{7-6-2008}

\section{Coordinates:}

\begin{tabular}{|l|l|l|}
\hline $30-3-2006$ & $13-9-2007$ & $27-6-2008$ \\
$\mathrm{~N} 31^{\circ} 1^{\prime} 5.70^{\prime \prime}$ & $\mathrm{N} 31^{\circ} 1^{\prime} 5.03^{\prime \prime}$ & N31 $11^{\circ} 5.03^{\prime \prime}$ \\
E103 $^{\circ} 35^{\prime} 51.25^{\prime \prime}$ & E103 $35^{\prime} 51.63^{\prime \prime}$ & E103 $35^{\prime} 51.22^{\prime \prime}$ \\
& & \\
\hline
\end{tabular}

Figure 9: Compeer tow images, before and after earth 5/12/2008.

same direction in recent 40 years and when there was a change in the direction of plate tectonics there was an earthquake in Sichuan, or on Tibet plate, but most of the earthquakes were in the region between plate Sichuan and Tibet plate. For Wenchuan, The results show that the DEM is useful for morphometric analysis. And how much the plate move on vertical direction, which related to the horizontal changes, that's helping to understand the mechanism of plate movements better. The idea is to compare between tow Dem images from the same satellite. The result will become better if there are images of the same area during every year.

- Remote sensing data are useful to find out the distribution places of ground GPS that increase the accuracy of the results and making correlation between GPS on the ground with remote sensing data to make our understanding about Neotectonics mechanism better.

- There is always a movement of the plates tectonic and of course the change in its directions and changes in speed will not be so fast, but as unknown, it will take a period of time, when the occurrence of earthquakes as known as it is the result of an impact between the plates tectonic, that the two plates are moving in different directions, and these trends are not consistent Had fixed. As well as for the occurrence of splay between plates tectonic with a speed that is greater than the other one. By monitoring the movements and changes in trends and at the tectonically active regions can determine what led to the region most vulnerable to the earthquake.

- This style of work can be carried out only on the land. 


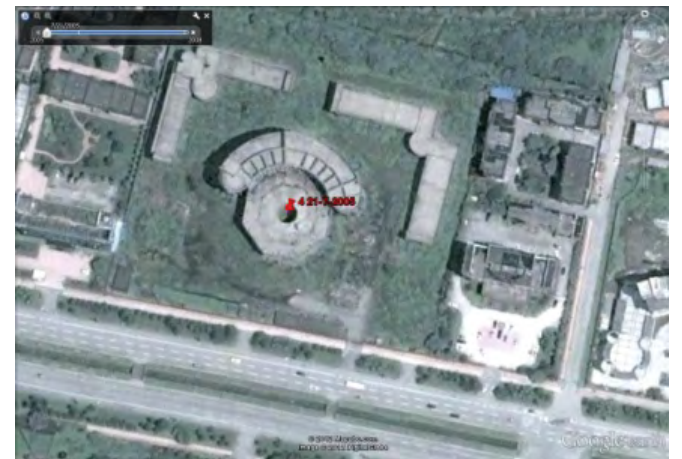

21-7-2005

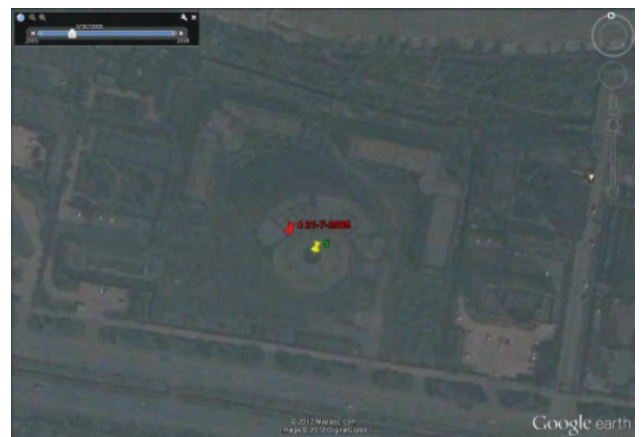

30-3- 2006

\section{COORDINATED:}

\begin{tabular}{l|l|l|}
\hline $21-7-2005$ & $30-3-2006$ & $27-6-2008$ \\
$\mathrm{~N} 30^{\circ} 59^{\prime} 37.80^{\prime \prime}$ & $\mathrm{N} 30^{\circ} 59^{\prime} 37.41 " \mathrm{~N}$ & $30^{\circ} 59^{\prime} 37.16^{\prime \prime} \mathrm{N}$ \\
$\mathrm{E} 103^{\circ} 38^{\prime} 3.97^{\prime \prime}$ & $\mathrm{E} 103^{\circ} 38^{\prime} 4.50^{\prime \prime} \mathrm{E}$ & $103^{\circ} 38^{\prime} 4.09^{\prime \prime} \mathrm{E}$ \\
& & \\
\hline
\end{tabular}

Figure 10: Compeer tow images, before and after earth 5/12/2008.
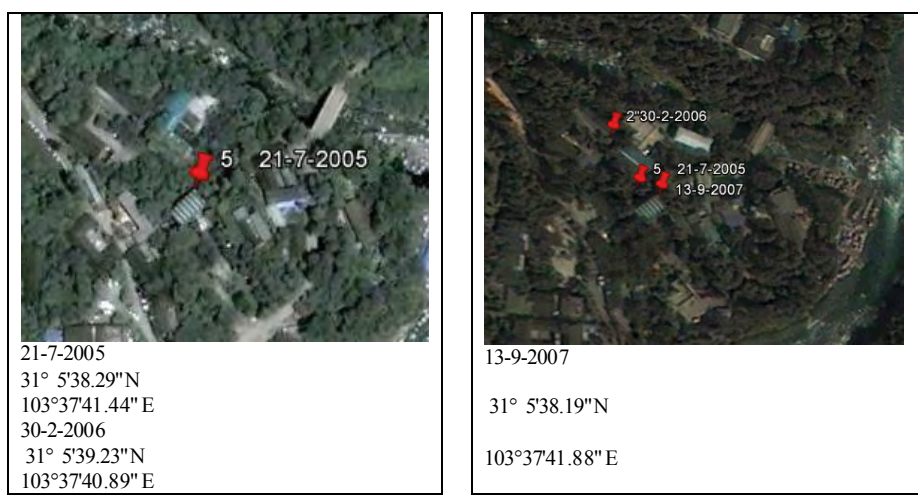

13-9-2007

$31^{\circ} 5^{\prime} 38.19^{\prime \prime} \mathrm{N}$

$103^{\circ} 37^{\prime} 41.88^{\prime \prime} \mathrm{E}$
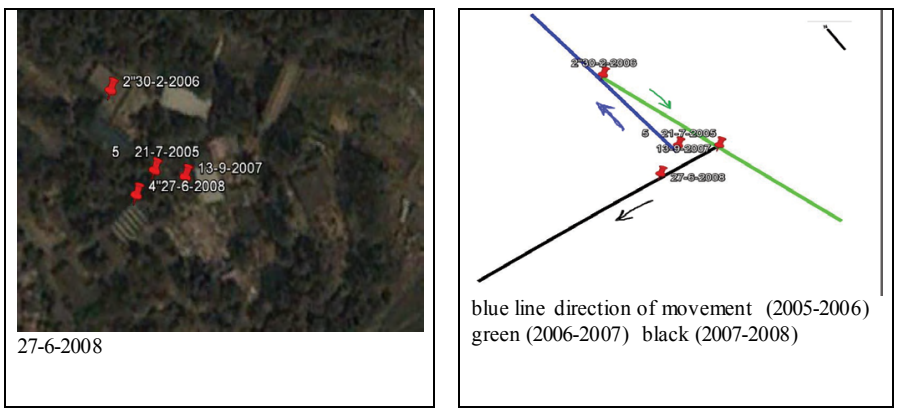

Figure 11: Compeer tow images, before and after earth 5/12/2008 


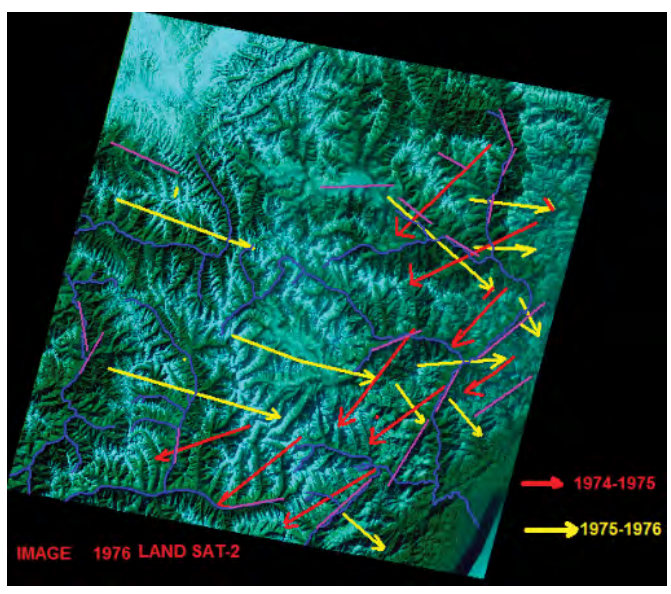

Figure 12: Direction of plate movements (1974-1976).

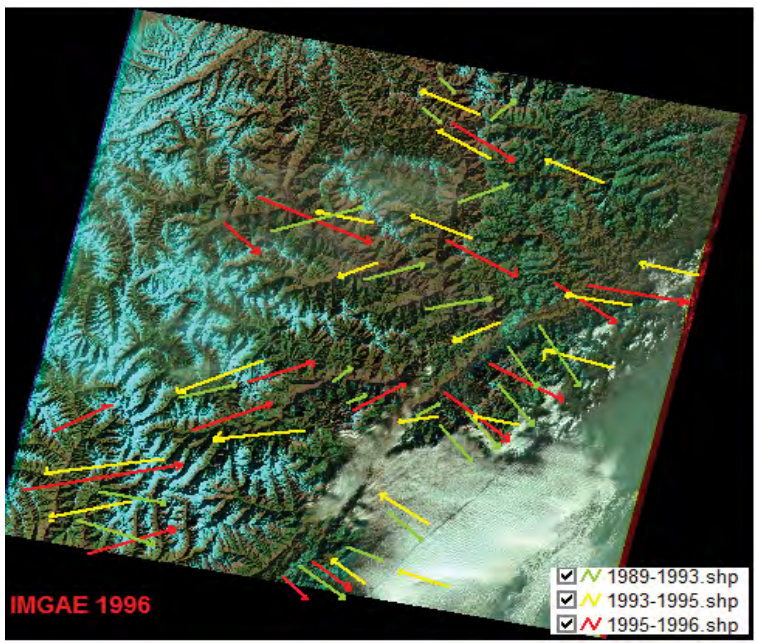

Figure 13: Image direction (1989-1996).

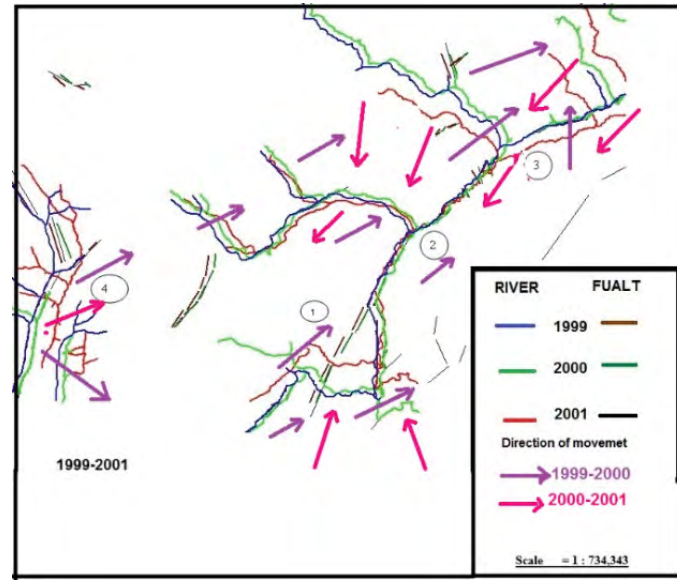

Figure 14: Direction of movements from (1999-2001) 


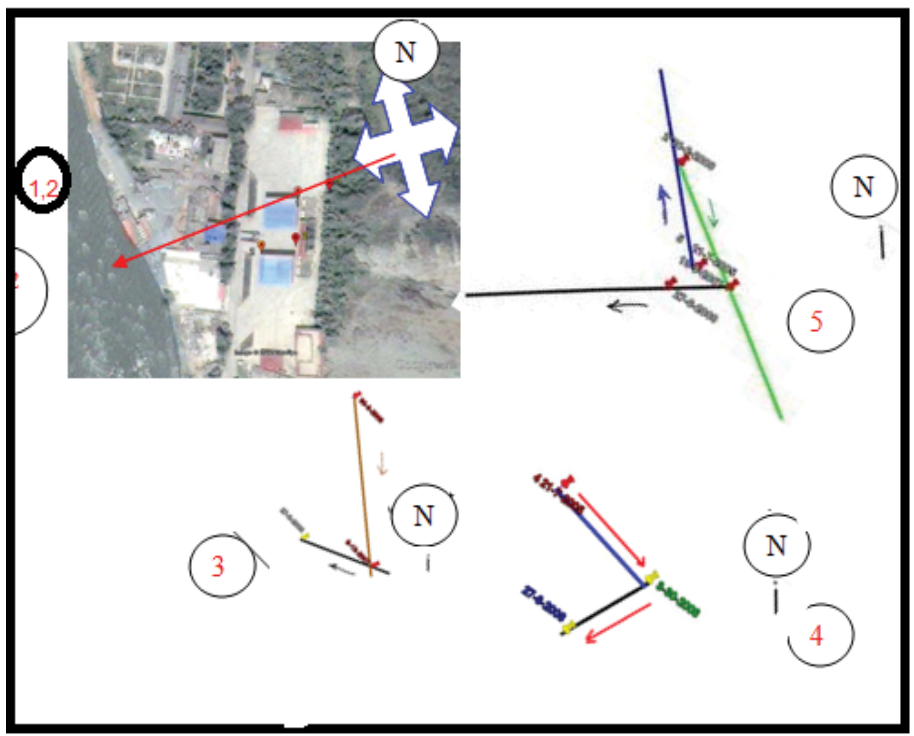

Figure15: Direction of movements from 2005-jun 2008(Horizontal movements using Google earth).
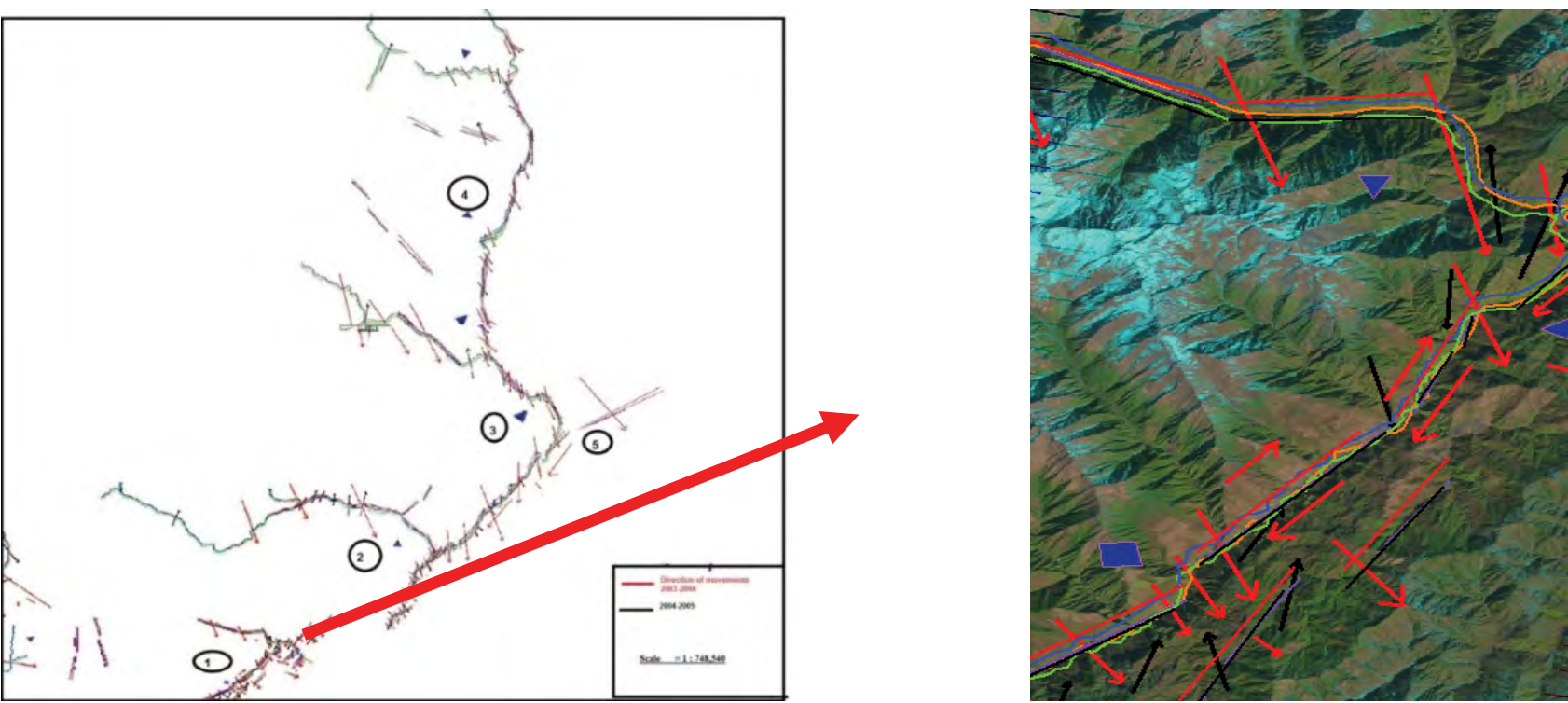

Figure 16: Direction of movement from (2003-2005).

- As for vertical changes due it depend on DEM image may some human activity or Erosion and sedimentation effect.

\section{References}

1. Tectonic Background of the Wenchuan Earthquake Yunsheng Wang, Runqiu Huang, Yonghong Luo, Hongbiao Xu, Shitian Wang, Liangwen Jiang and Yusheng (2008) LiState Key Lab. Of Geohazard Prevention, Chengdu University of Technology, Chengdu China* Sol S, Meltzer A, Burgmann R, Van der Hilst RD, King R, Chen Z, Koons P, Lev E, Liu Y, Zeitler P.K, Zhang X, Zhang, J, Zurek B, Geodynamics of southeastern Tibet from seismic anisotropy and geodesy. Geology 35: 563-556.
2. Zhang W, Lin J, Peng J, Lu Q, State Key Laboratory of Hydraulics and Mountain River Engineering, Sichuan University, Chengdu 610065, China Institute of Geographic Sciences and Natural Resources Research, Chinese Academy of Sciences, Beijing 100101, China.

3. Pinghua H, Ying $H(2014)$ Institute of Mountain Hazards and Environment. Mountain research and development 34: 167-169 